University of Wollongong

Research Online

Australian Institute for Innovative Materials -

Papers

Australian Institute for Innovative Materials

$1-1-2017$

\title{
First-order magneto-structural transition and magnetocaloric effect in $\mathrm{Mn}(\mathrm{Co} 0.96 \mathrm{Fe} 0.04) \mathrm{Ge}$
}

Qing Yon Ren

University of New South Wales

Wayne D. Hutchison

University of New South Wales

Jian Li Wang

University of Wollongong, jianli@uow.edu.au

Andrew J. Studer

Australian Nuclear Science and Technology Organisation

Stewart J. Campbell

University of New South Wales, stewart.campbell@adfa.edu.au

Follow this and additional works at: https://ro.uow.edu.au/aiimpapers

Part of the Engineering Commons, and the Physical Sciences and Mathematics Commons

Research Online is the open access institutional repository for the University of Wollongong. For further information contact the UOW Library: research-pubs@uow.edu.au 


\title{
First-order magneto-structural transition and magnetocaloric effect in $\mathrm{Mn}(\mathrm{Co0} .96 \mathrm{Fe} 0.04) \mathrm{Ge}$
}

\author{
Abstract \\ The magnetic properties and magnetic structure of an as-prepared $\mathrm{Mn}(\mathrm{Co} 0.96 \mathrm{Fe} 0.04) \mathrm{Ge}$ sample has \\ been investigated by powder neutron diffraction as well as $\mathrm{X}$-ray diffraction and magnetisation \\ measurements. The sample has a ferromagnetic structure in the low-temperature orthorhombic phase \\ and a magneto-structural transition at 299 (1) $\mathrm{K}$ to the high-temperature paramagnetic hexagonal phase. \\ This transition occurs at a higher temperature than for as-prepared (Mn0.96Fe0.04)CoGe (TM = 239 (1) \\ $\mathrm{K})$. Increased occupancy by Fe of the Co (4c) site rather than the Mn (4c) site results in this smaller \\ suppression of the structural transition temperature away from that of undoped MnCoGe. It was found \\ that chemical pressure increased the Curie temperature View the MathML sourceTCorth in the \\ orthorhombic phase from 355 (5) $\mathrm{K}$ in $\mathrm{Mn}(\mathrm{Co} 0.96 \mathrm{Fe} 0.04) \mathrm{Ge}$ to 379 (6) $\mathrm{K}$ in MnCoGe. \\ $\mathrm{Mn}(\mathrm{Co} 0.96 \mathrm{Fe}$ 0.04) Ge exhibits a large magnetocaloric effect around the magneto-structural transition, \\ View the MathML source- $\Delta$ Smpeak $=11$ (2) J kg-1 K-1 and RC $=187$ (30) J kg-1 with $\mu 0 \Delta \mathrm{H}=5 \mathrm{~T}$. The \\ magneto-structural transition is a first order transition as demonstrated by master curve analysis.

\section{Disciplines} \\ Engineering | Physical Sciences and Mathematics

\section{Publication Details} \\ Ren, Q. Y., Hutchison, W. D., Wang, J. L., Studer, A. J. \& Campbell, S. J. (2017). First-order magneto- \\ structural transition and magnetocaloric effect in $\mathrm{Mn}(\mathrm{Co0} .96 \mathrm{Fe} 0.04) \mathrm{Ge}$. Journal of Alloys and \\ Compounds, 693 32-39.
}




\title{
First-order magneto-structural transition and magnetocaloric
}

\author{
effect in $\mathrm{Mn}\left(\mathrm{Co}_{0.96} \mathrm{Fe}_{0.04}\right) \mathrm{Ge}$
}

\author{
Q.Y. Ren ${ }^{\mathrm{a},}$, W.D. Hutchison ${ }^{\mathrm{a}}$, J.L. Wang ${ }^{\mathrm{b}}$, A.J. Studer ${ }^{\mathrm{c}}$, and S.J. Campbell ${ }^{\mathrm{a}}$ \\ ${ }^{a}$ School of Physical, Environmental and Mathematical Sciences, The University of New South Wales, \\ Canberra, ACT 2600, Australia \\ ${ }^{\mathrm{b}}$ Institute for Superconductivity and Electronic Materials, University of Wollongong, Wollongong, \\ NSW 2522, Australia \\ ${ }^{\mathrm{c}}$ Bragg Institute, Australian Nuclear Science and Technology Organisation, Lucas Heights, NSW \\ 2234, Australia
}

\begin{abstract}
:
The magnetic properties and magnetic structure of an as-prepared $\mathrm{Mn}\left(\mathrm{Co}_{0.96} \mathrm{Fe}_{0.04}\right) \mathrm{Ge}$ sample has been investigated by powder neutron diffraction as well as x-ray diffraction and magnetisation measurements. The sample has a ferromagnetic structure in the lowtemperature orthorhombic phase and a magneto-structural transition at 299(1) K to the hightemperature paramagnetic hexagonal phase. This transition occurs at a higher temperature than for as-prepared $\left(\mathrm{Mn}_{0.96} \mathrm{Fe}_{0.04}\right) \mathrm{CoGe}\left(T_{\mathrm{M}}=239(1) \mathrm{K}\right)$. Increased occupancy by $\mathrm{Fe}$ of the Co (4c) site rather than the Mn (4c) site results in this smaller suppression of the structural transition temperature away from that of undoped MnCoGe. It was found that chemical pressure increased the Curie temperature $T_{\mathrm{C}}^{\text {orth }}$ in the orthorhombic phase from $355(5) \mathrm{K}$ in $\mathrm{Mn}\left(\mathrm{Co}_{0.96} \mathrm{Fe}_{0.04}\right) \mathrm{Ge}$ to $379(6) \mathrm{K}$ in MnCoGe. $\mathrm{Mn}\left(\mathrm{Co}_{0.96} \mathrm{Fe}_{0.04}\right) \mathrm{Ge}$ exhibits a large magnetocaloric effect around the magneto-structural transition, $-\Delta S_{\mathrm{m}}^{\text {peak }}=11(2) \mathrm{J} \mathrm{kg}^{-1} \mathrm{~K}^{-1}$ and $R C=187(30) \mathrm{J} \mathrm{kg}^{-1}$ with $\mu_{0} \Delta H=5 \mathrm{~T}$. The magneto-structural transition is a first order transition as demonstrated by master curve analysis.
\end{abstract}

Corresponding author. Tel.: +61 26268 8764; Fax: +61 262688786 .

E-mail address: qingyong.ren@student.adfa.edu.au (Q.Y. Ren).

Keywords: Neutron powder diffraction; Magneto-structural transition; Chemical pressure; Magnetocaloric effect; First-order transition. 


\section{INTRODUCTION:}

Magnetic refrigeration based on the magnetocaloric effect (MCE) has attracted increasing attention in recent decades due to its environmental friendly and energy-saving advantages [1-3]. With practical applications in mind, relatively inexpensive materials that exhibit a large MCE are required. Following on from the discovery of a giant magnetocaloric effect in $\mathrm{Gd}_{5} \mathrm{Si}_{2} \mathrm{Ge}_{2}$ [4], at least six types of materials that exhibit coupling of magnetic and structural transitions - a magneto-structural transition - have been explored for their potentially high magnetocaloric performance [4-9]. The list of these six groups of materials include: $\mathrm{LaFe}_{11.5} \mathrm{Si}_{1.5} \mathrm{H}_{\mathrm{x}}$ [5], $\mathrm{MnFeP}_{1-\mathrm{x}} \mathrm{As}_{\mathrm{x}}$ [6], $\mathrm{Mn}_{1-\mathrm{x}} \mathrm{Fe}_{\mathrm{x}} \mathrm{As}$ alloys [7], Ni-Mn-In-(Co) Heusler alloys [8], MnCoGe-based compounds [9] as well as $\mathrm{Gd}_{5} \mathrm{Si}_{2} \mathrm{Ge}_{2}$ related materials [4]. In cases involving a magneto-structural transition, a change in magnetic field can induce simultaneously changes in both the magnetic and lattice entropies in materials, thereby bringing about a large magnetocaloric effect [8].

MnCoGe-based compounds are a family of promising materials with a large magnetocaloric effect; they are relatively low cost compared with rare earth compounds and exhibit magneto-structural transitions over the important temperature region around room temperature ( $275 \mathrm{~K}$ to $345 \mathrm{~K}$ ) [9]. MnCoGe-based compounds commonly undergo a change in structure at the martensitic reverse transformation temperature $T_{\mathrm{M}}$, from a low-temperature orthorhombic phase (TiNiSi-type structure, Pnma) to a high-temperature hexagonal $\left(\mathrm{Ni}_{2} \mathrm{In}\right.$ type structure, $P 6_{3} / m m c$ ) phase between $T_{\mathrm{M}} \sim 398 \mathrm{~K}$ and $T_{\mathrm{M}} \sim 458 \mathrm{~K}$ [10]. The orthorhombic phase has a ferromagnetic structure below a Curie temperature near $350 \mathrm{~K}$ (e.g. $T_{\mathrm{C}}^{\text {orth }} \sim 345 \mathrm{~K}$ [11]; $\left.T_{\mathrm{C}}^{\text {orth }} \sim 355 \mathrm{~K}[10]\right)$. The structural transition temperature at $T_{\mathrm{M}}$ is sensitive to external pressure [12], vacancies in the Co and Mn sites [13, 14], as well as variation in chemical environment resulting from introduction of interstitial atoms [9] or element substitution for Mn, Co or Ge [15-22]. All of these factors can drive $T_{\mathrm{M}}$ towards lower temperatures, e.g. a 
suitable partial substitution for Mn or Co favours stabilisation to lower temperature of the hexagonal phase which has a ferromagnetic ordering temperature of $T_{\mathrm{C}}^{\text {hex }} \sim 275 \mathrm{~K}$ [23]. For a case that the resulting $T_{\mathrm{M}}$ is engineered to lie within the temperature range between $T_{\mathrm{C}}^{\mathrm{hex}}$ and $T_{\mathrm{C}}^{\text {orth }}$, a magneto-structural transition from the ferromagnetic orthorhombic structure to the paramagnetic hexagonal structure is created, thereby offering scope for a large magnetocaloric effect at the transition [14].

Recent studies have established that Fe is an effective substitute for $\mathrm{Mn}$ in MnCoGe in driving $T_{\mathrm{M}}$ towards lower temperatures [24-28]. At the same time, Li et al. [24] also reported that substitution of Fe for Co can bring about coincidence of the magnetic and structural transitions. A martensitic reverse transformation temperature of $T_{\mathrm{M}}=304(1) \mathrm{K}$ was obtained for $\mathrm{Mn}\left(\mathrm{Co}_{0.96} \mathrm{Fe}_{0.04}\right) \mathrm{Ge}\left({ }^{57} \mathrm{Fe}\right)$ in the as-prepared state by x-ray diffraction measurements in an initial investigation of Fe dopant occupation using ${ }^{57} \mathrm{Fe}$ Mössbauer spectroscopy [29]. Here we present a comprehensive investigation of the magnetic properties and magnetocaloric behaviour of $\mathrm{Mn}\left(\mathrm{Co}_{0.96} \mathrm{Fe}_{0.04}\right) \mathrm{Ge}$ using $\mathrm{x}$-ray diffraction, neutron diffraction and magnetisation measurements. The resulting magnetic transitions are also evaluated in terms of magnetocaloric entropy and refrigeration capacity $(R C)$, and the nature of the transition is investigated using master curve analysis [30, 31].

\section{EXPERIMENTAL:}

The polycrystalline $\mathrm{Mn}\left(\mathrm{Co}_{0.96} \mathrm{Fe}_{0.04}\right) \mathrm{Ge}$ sample was prepared by arc melting stoichiometric amounts of $\mathrm{Mn}, \mathrm{Co}, \mathrm{Ge}$ and $\mathrm{Fe}(>99.95 \mathrm{wt} \%)$ in an argon arc furnace with $3 \%$ excess of Mn added to compensate for the mass loss of Mn during sample preparation. The ingot was re-melted five times to improve sample homogeneity. The quality of the sample and its crystallographic structure were studied by x-ray powder diffraction measurements at room temperature with $\mathrm{Cu}-\mathrm{K}_{\alpha}$ radiation. The orthorhombic and hexagonal structures were 
found to be present in the sample at room temperature as expected with no discernible impurity. The neutron diffraction measurements were carried out over the temperature range from $5 \mathrm{~K}$ to $450 \mathrm{~K}$ at $5 \mathrm{~K}$ steps on the High-Intensity Powder Diffractometer Wombat $(\lambda=$ $2.4205 \AA$ ) at the OPAL reactor, Australia. Rietveld refinements of the diffraction patterns were carried out using FullProf package [32, 33]. Temperature dependent magnetisation measurements were performed in a magnetic field of $0.01 \mathrm{~T}$ from $5 \mathrm{~K}$ to $320 \mathrm{~K}$ using a Quantum Design Physical Properties Measurement System (PPMS) with the field dependence of magnetisation collected in magnetic fields up to $8 \mathrm{~T}$ at $5 \mathrm{~K}, 100 \mathrm{~K}$ and $200 \mathrm{~K}$ and over the temperature range $240 \mathrm{~K}$ to $320 \mathrm{~K}$ in $5 \mathrm{~K}$ steps.

\section{RESULTS:}

\subsection{Magnetisation}

Magnetisation curves collected in a magnetic field of $0.01 \mathrm{~T}$ are shown in Fig. 1: the data were collected as follows - on heating after zero-field cooling (ZFC), on cooling (FC) and on heating $(\mathrm{FH})$ in a field. The sample exhibits a transition around $300 \mathrm{~K}$ from a low temperature ferromagnetic state to a high temperature paramagnetic state. The magnetic state change temperatures are found to be $T_{\mathrm{m}}^{\mathrm{H}}=305(4) \mathrm{K}$ and $T_{\mathrm{m}}^{\mathrm{C}}=295(4) \mathrm{K}$ on heating and cooling respectively, as determined from the differential magnetisation curves of $d M / d T$ versus $T$. The hysteresis $\Delta T_{\text {hys }}=10(5) \mathrm{K}$ evident in the magnetisation curves indicates that this magnetic transition is first-order.

\subsection{Magnetic structures}

The thermal contour image of powder neutron diffraction patterns for $\mathrm{Mn}\left(\mathrm{Co}_{0.96} \mathrm{Fe}_{0.04}\right) \mathrm{Ge}$ over a $2 \theta$ range from $28^{\circ}$ to $55^{\circ}$ is shown in Fig. 2(a). A phase transition from an orthorhombic TiNiSi-type structure at low temperature to a hexagonal $\mathrm{Ni}_{2} \mathrm{In}$-type structure at 
high temperature was observed around the martensitic reverse transformation temperature $T_{\mathrm{M}}$ $=299(1) \mathrm{K}$.

Neutron diffraction patterns of $\mathrm{Mn}\left(\mathrm{Co}_{0.96} \mathrm{Fe}_{0.04}\right) \mathrm{Ge}$ at selected temperatures up to $250 \mathrm{~K}$ are shown in Fig. 2(b). All of the diffraction peaks in Fig. 2(b) are identified with the orthorhombic phase. As is evident from the thermal contour plot of Fig. 2(a), a transition from the orthorhombic phase to the hexagonal phase occurs around $T_{\mathrm{M}}=299(1) \mathrm{K}$. The variations of the intensities of the orthorhombic $(011)^{\text {orth }}$ peak as well as the hexagonal $(002)^{\text {hex }}$ peaks over the temperature range $5 \mathrm{~K}$ to $450 \mathrm{~K}$ are shown in Fig. 2(c). In addition to the transition around $299(1) \mathrm{K}$, the increase in intensity of the $(011)^{\text {orth }}$ peak below $\sim 250 \mathrm{~K}$ is consistent with an increasing contribution from magnetic scattering below $\sim 250 \mathrm{~K}$. It is noted that the absence of additional peaks in the patterns rules out the possibility of an antiferromagnetic or complex incommensurate magnetic structure.

Given the magnetic state change in the $\mathrm{Mn}\left(\mathrm{Co}_{0.96} \mathrm{Fe}_{0.04}\right) \mathrm{Ge}$ sample (Fig. 1) and the occurrence of magnetic scattering in the orthorhombic phase, the magnetic structure of the $\mathrm{Mn}\left(\mathrm{Co}_{0.96} \mathrm{Fe}_{0.04}\right) \mathrm{Ge}$ sample below the structural transition temperature $T_{\mathrm{M}}$ was investigated via irreducible representational analysis [34, 35] using the BASIREPS program in the FullProf suite. For the 4c site (Mn and Co atoms both occupy 4c sites) in the orthorhombic structure (Pnma), the decomposition of the magnetic representation comprises eight representations:

$$
\Gamma_{\text {Mag }}^{4 c}=1 \Gamma_{1}+2 \Gamma_{2}+2 \Gamma_{3}+1 \Gamma_{4}+1 \Gamma_{5}+2 \Gamma_{6}+2 \Gamma_{7}+1 \Gamma_{8}
$$

The basis vectors of these irreducible representations are given in Table 1. All of these representation models were simulated and comparison of these simulated results with the neutron diffraction patterns indicated that the representation model $\Gamma_{3}$ (collinear

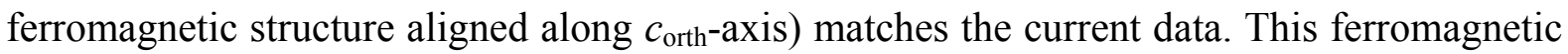


structure is also consistent with the magnetisation curves of Fig. 1. Three phases were used in the refinements corresponding to: the nuclear scattering from the orthorhombic and hexagonal phases, and the magnetic scattering from the magnetic structure associated with the orthorhombic phase (the magnetic scattering contribution from the hexagonal phase was ignored in the refinement due to the relatively small fraction of this phase $(<10 \mathrm{wt} \%)$ in the sample below the Curie temperature $T_{\mathrm{C}}^{\text {hex }} \sim 275 \mathrm{~K}$ [23]). The Rietveld refinements of the $5 \mathrm{~K}$, $300 \mathrm{~K}$ and $450 \mathrm{~K}$ patterns for $\mathrm{Mn}\left(\mathrm{Co}_{0.96} \mathrm{Fe}_{0.04}\right) \mathrm{Ge}$ are shown in Fig. 3(a), 3(b) and 3(c) respectively, with results of the Rietveld refinements summarised in Table 2. Compared with a model that considers that both the $\mathrm{Mn}$ and Co sublattices in the orthorhombic structure carry a magnetic moment, the model in which only the Mn sublattice carries a magnetic moment along the $c_{\text {orth-axis }}$ is found to be consistent with the results from the saturated magnetisation measurements presented in Section 3.4 (Table 3). This indicated that the magnetic moment in $\mathrm{Mn}\left(\mathrm{Co}_{0.96} \mathrm{Fe}_{0.04}\right) \mathrm{Ge}$ mainly comes from the $\mathrm{Mn}$ sublattice and that magnetic moment on the Co sublattice is so small that it cannot be resolved by powder neutron diffraction, similar to the case of as-prepared $\left(\mathrm{Mn}_{0.98} \mathrm{Fe}_{0.02}\right) \mathrm{CoGe}$ [28]. Thus only the magnetic moment on the Mn sublattice in the orthorhombic phase was considered in the Rietveld refinement of the neutron diffraction patterns.

\subsection{Phase evolutions and magneto-structural transition}

The neutron diffraction patterns and refinements of as-prepared $\mathrm{Mn}\left(\mathrm{Co}_{0.96} \mathrm{Fe}_{0.04}\right) \mathrm{Ge}$ in Fig. 3 (see also Table 2) encapsulate the different structural aspects of the compound. At $450 \mathrm{~K}$, $\mathrm{Mn}\left(\mathrm{Co}_{0.96} \mathrm{Fe}_{0.04}\right) \mathrm{Ge}$ exhibits primarily the paramagnetic hexagonal structure (Fig. 3(a)). By comparison, in the region of the phase transition - at $300 \mathrm{~K}$ for example - the sample comprises $48(2) \mathrm{wt} \%$ of the orthorhombic structure with $52(2) \mathrm{wt} \%$ of the hexagonal phase observed (Fig. 3(b)). Ferromagnetic scattering from the orthorhombic phase also contributes to the diffraction pattern at $300 \mathrm{~K}$ as a result of the Mn moment of 2.3(2) $\mu_{\mathrm{B}}$ at this 
temperature. On cooling $\mathrm{Mn}\left(\mathrm{Co}_{0.96} \mathrm{Fe}_{0.04}\right) \mathrm{Ge}$ to $5 \mathrm{~K}$, as shown in Fig. 3(c), the sample has transformed primarily to the orthorhombic phase (98(3) wt $\%$ ) with ferromagnetic structure and a magnetic moment of 3.6(1) $\mu_{\mathrm{B}}$ on the Mn sublattice.

The temperature dependences of the lattice constants and cell volume derived from the Rietveld refinements of the neutron diffraction patterns ( $5 \mathrm{~K}$ to $450 \mathrm{~K}$ ) of $\mathrm{Mn}\left(\mathrm{Co}_{0.96} \mathrm{Fe}_{0.04}\right) \mathrm{Ge}$ are shown in Fig. 4(a). Similar to other MnCoGe-based compounds [10, 28], the relationship between the lattice parameters of the orthorhombic and hexagonal structures are: $a_{\mathrm{orth}} \sim c_{\text {hex }}$, $b_{\text {orth }} \sim a_{\text {hex }}, c_{\text {orth }} / \sqrt{3} \sim a_{\text {hex }}$ and $V_{\text {orth }} / 2 \sim V_{\text {hex. }}$ In addition, a volume reduction by $4.0 \%(\Delta V / V=$ $\left.\left(V_{\text {orth }} / 2-V_{\text {hex }}\right) /\left(V_{\text {orth }} / 2\right)\right)$ occurs from the low-temperature orthorhombic structure to the hightemperature hexagonal structure. Such large volume differences associated with a magnetostructural transition can contribute to increased structural entropies, leading to an increased magnetocaloric effect [36]. In addition, such structural changes provide scope to use these materials for applications requiring negative thermal expansion [37].

The orthorhombic and hexagonal phase fractions in the region of the transition temperature $T_{\mathrm{M}}$ are shown in Fig. 4(b). A fit to the transition region using a Gaussian function [28] led to a mean structural transition temperature $T_{\mathrm{M}}=299(1) \mathrm{K}$ with a full width at half maximum (FWHM) of $29(1) \mathrm{K}$. The present value $T_{\mathrm{M}}=299(1) \mathrm{K}$ is much smaller than $T_{\mathrm{M}}$ $\sim 398 \mathrm{~K}$ for $\mathrm{MnCoGe}$ [10]. It is accepted that the substitution of $\mathrm{Fe}$ (of atomic radius $\left(\mathrm{r}_{\mathrm{Fe}}=\right.$ $1.25 \AA[38])$ for $\mathrm{Co}\left(\mathrm{r}_{\mathrm{Co}}=1.26 \AA\right)$ or $\mathrm{Mn}\left(\mathrm{r}_{\mathrm{Mn}}=1.39 \AA\right)$ in MnCoGe brings about changes due to two factors: (1) a pressure effect (this chemical pressure comes from size effect due to different atomic radii) and (2) an electronic effect. Both effects will play a role in the variation in the transition temperature. It has been reported that application of external pressure drives a structural change from the orthorhombic structure to the hexagonal structure and a shift in the transition temperature $T_{\mathrm{M}}$ to lower temperature $\left(d T_{\mathrm{M}} / d p=-11.6 \mathrm{~K} / \mathrm{kbar}\right)$ 
[12]. With respect to $\mathrm{MnCoGe}$ as the reference, we consider the influence of the reduction in unit cell volume due to Fe substitution to be analogous to the effects of chemical pressure. Here the Murnaghan equation was used to describe the lattice response to chemical pressure [39]:

$$
P(V)=\frac{B_{0}}{B_{0}^{\prime}}\left(\left(\frac{V_{0}}{V}\right)^{B_{0}^{\prime}}-1\right)
$$

$P$ is the pressure correlated to the change of volume $V, B_{0}$ is bulk modulus $B=-V(\delta P / \delta V)_{T}$ at ambient pressure, and $B^{\prime}\left(B_{0}^{\prime}\right)$ is used to describe the pressure dependence of the bulk modulus $B$ (at ambient pressure) and has a relationship:

$$
B^{\prime}=B_{0}+B_{0}^{\prime} P
$$

Based on the results for $\mathrm{Mn}_{0.92} \mathrm{Fe}_{0.08} \mathrm{CoGe}$ [40] for which bulk modulus $B_{0}=112.2 \mathrm{GPa}$ and $B^{\prime}=7.2$, the chemical pressure in the present case of the as-prepared $\mathrm{Mn}\left(\mathrm{Co}_{0.96} \mathrm{Fe}_{0.04}\right) \mathrm{Ge}$ sample was determined as $5.2 \mathrm{kbar}$. Here, $V_{\text {orth }}=160.6(2) \AA^{3}$ for pure MnCoGe at room temperature as determined by x-ray diffraction is used as $V_{0}$ in Eq. 2 while for $\operatorname{Mn}\left(\mathrm{Co}_{0.96} \mathrm{Fe}_{0.04}\right) \mathrm{Ge}, V_{\text {orth }}=159.89(6) \AA^{3}$ at $298 \mathrm{~K}$ as determined from the neutron diffraction data. Then the expected $T_{\mathrm{M}}$ for $\mathrm{Mn}\left(\mathrm{Co}_{0.96} \mathrm{Fe}_{0.04}\right) \mathrm{Ge}$ can be derived to be $338 \mathrm{~K}$ which is larger than the experimental value here $\left(T_{\mathrm{M}}=299(1) \mathrm{K}\right)$. So it is clear that the resultant variation of electronic configuration in $\mathrm{Mn}\left(\mathrm{Co}_{0.96} \mathrm{Fe}_{0.04}\right) \mathrm{Ge}$ also plays a role on stabilisation of the hexagonal phase [41].

In addition, it is noted that present value $T_{\mathrm{M}}=299(1) \mathrm{K}$ is similar to the transition temperature 304(1) K obtained for as-prepared $\mathrm{Mn}\left(\mathrm{Co}_{0.96} \mathrm{Fe}_{0.04}\right) \mathrm{Ge}\left({ }^{57} \mathrm{Fe}\right)$ doped with ${ }^{57} \mathrm{Fe}[29]$, while much higher than $239(1) \mathrm{K}$ for as-prepared $\left(\mathrm{Mn}_{0.96} \mathrm{Fe}_{0.04}\right) \mathrm{CoGe}\left({ }^{57} \mathrm{Fe}\right)$ [29]. As demonstrated in our Mössbauer spectroscopy investigation [29], a greater fraction of the Fe 
atoms occupy the $\mathrm{Co}$ site in $\mathrm{Mn}\left(\mathrm{Co}_{0.96} \mathrm{Fe}_{0.04}\right) \mathrm{Ge}\left({ }^{57} \mathrm{Fe}\right)$ compared with $\left(\mathrm{Mn}_{0.96} \mathrm{Fe}_{0.04}\right) \mathrm{CoGe}\left({ }^{57} \mathrm{Fe}\right)$. It is also noted that a larger unit cell volume is obtained in $\operatorname{Mn}\left(\mathrm{Co}_{0.96} \mathrm{Fe}_{0.04}\right) \mathrm{Ge}$, e.g. $V_{\text {orth }}=158.7(1) \AA^{3}$ at $20 \mathrm{~K}$ compared with $V_{\text {orth }}=158.0(1) \AA^{3}$ in $\left(\mathrm{Mn}_{0.96} \mathrm{Fe}_{0.04}\right) \mathrm{CoGe}\left({ }^{57} \mathrm{Fe}\right)$ at $20 \mathrm{~K}$. It is obvious that the substitution of $\mathrm{Fe}$ for Co corresponds to a smaller chemical pressure than the substitution of Fe for $\mathrm{Mn}$ and hence a higher $T_{\mathrm{M}}$ in $\operatorname{Mn}\left(\mathrm{Co}_{0.96} \mathrm{Fe}_{0.04}\right) \mathrm{Ge}\left(T_{\mathrm{M}}=299(1) \mathrm{K}\right)$ compared with $\left(\mathrm{Mn}_{0.96} \mathrm{Fe}_{0.04}\right) \operatorname{CoGe}\left({ }^{57} \mathrm{Fe}\right)\left(T_{\mathrm{M}}=239(1) \mathrm{K}\right)$ [29].

The magnetic moment values on the Mn sublattice in the orthorhombic structure derived from the neutron refinements are shown over the temperature range from $5 \mathrm{~K}$ to $300 \mathrm{~K}$ in Fig. 4(c). On the basis that in isolation both the orthorhombic and hexagonal phases in MnCoGebased compounds exhibit a second-order ferromagnetic transition [9], we have fitted the magnetic moment data of Fig. 4(c) with a Brillouin function. The solid line in Fig. 4(c) $\left(\mathrm{Mn}^{2+}\right.$, $\mathrm{J}=\mathrm{S}=5 / 2$ ), leads to an extrapolated Curie temperature for the orthorhombic structure of $T_{\mathrm{C}}^{\text {orth }}=379(6) \mathrm{K}$; this value is higher than $T_{\mathrm{C}}^{\text {orth }}=355(5) \mathrm{K}$ reported for MnCoGe [10] with the difference considered to occur as a result of chemical pressure in the present $\mathrm{Fe}$ containing sample. It was demonstrated that applied pressure can drive the Curie temperature higher in MnCoGe-based compounds by $\mathrm{d} T_{\mathrm{C}} / \mathrm{d} p=3.9 \mathrm{~K} / \mathrm{kbar}[11]$. As discussed above, the chemical pressure in the present case of the as-prepared $\mathrm{Mn}\left(\mathrm{Co}_{0.96} \mathrm{Fe}_{0.04}\right) \mathrm{Ge}$ sample was determined as $5.2 \mathrm{kbar}$. The change of Curie temperature $T_{\mathrm{C}}^{\text {orth }}$ due to chemical pressure was calculated as $\Delta T_{\mathrm{C}}^{\text {orth }}=20 \mathrm{~K}$, which is of the same order as the difference between $T_{\mathrm{C}}^{\text {orth }}=$ 379(6) $\mathrm{K}$ for $\mathrm{Mn}\left(\mathrm{Co}_{0.96} \mathrm{Fe}_{0.04}\right) \mathrm{Ge}(\mathrm{Fig} .3(\mathrm{c}))$ and $T_{\mathrm{C}}^{\text {orth }}=355(5) \mathrm{K}$ reported for MnCoGe. In fact, this variation of $T_{\mathrm{C}}^{\text {orth }}$ caused by the chemical pressure is considered to occur as a result of the change of magnetic exchange interaction due to the magneto-volume effect on substitution of Fe for Co. 
The phase transition at 299(1) K - evident from analysis of the neutron diffraction patterns (Fig. 4) and from the contour image in Fig. 2(a) - takes place from the lowtemperature ferromagnetic orthorhombic phase to the high-temperature paramagnetic hexagonal phase. This simultaneous occurrence of magnetic and structural transitions leads to the magneto-structural transition.

\subsection{Magnetocaloric effect}

The isothermal magnetisation curves for $\mathrm{Mn}\left(\mathrm{Co}_{0.96} \mathrm{Fe}_{0.04}\right) \mathrm{Ge}$ over the temperature range $240 \mathrm{~K}$ to $320 \mathrm{~K}$ in $5 \mathrm{~K}$ steps are shown in Fig. 5(a). Based on these data, the isothermal magnetic entropy changes $\Delta S_{\mathrm{m}}$ with different magnetic field changes $\mu_{0} \Delta H$ (starting from $0 \mathrm{~T}$ ) were derived in the standard manner using the Maxwell function [1]:

$$
\Delta S_{\mathrm{m}}(T, \Delta H)=\mu_{0} \int_{H_{0}}^{H_{1}}\left(\frac{\partial M\left(T, H^{\prime}\right)}{\partial T}\right)_{H} \mathrm{~d} H^{\prime} .
$$

The isothermal magnetic entropy changes $-\Delta S_{\mathrm{m}}^{\text {peak }}$ are $4.2(8) \mathrm{J} \mathrm{kg}^{-1} \mathrm{~K}^{-1}$ and $11(2) \mathrm{J} \mathrm{kg}^{-1} \mathrm{~K}^{-1}$ at 302(4) $\mathrm{K}$ (Fig. 5(b)), for the magnetic field changes of $\mu_{0} \Delta H=2 \mathrm{~T}$ and $5 \mathrm{~T}$, respectively. Though $-\Delta S_{\mathrm{m}}^{\text {peak }}=11(2) \mathrm{J} \mathrm{kg}^{-1} \mathrm{~K}^{-1}\left(\mu_{0} \Delta H=5 \mathrm{~T}\right)$ is smaller than the value of $27.5 \mathrm{~J} \mathrm{~kg}^{-1} \mathrm{~K}^{-1}$ in annealed $\mathrm{Mn}\left(\mathrm{Co}_{0.94} \mathrm{Fe}_{0.06}\right) \mathrm{Ge}$ [24], it is comparable with $11.5 \mathrm{~J} \mathrm{~kg}^{-1} \mathrm{~K}^{-1}$ in annealed $\operatorname{Mn}\left(\mathrm{Co}_{0.97} \mathrm{Zn}_{0.03}\right) \mathrm{Ge}$ [42] and $10(2) \mathrm{J} \mathrm{kg}^{-1} \mathrm{~K}^{-1}$ in as-prepared $\left(\mathrm{Mn}_{0.98} \mathrm{Fe}_{0.02}\right) \mathrm{CoGe}$ [28].

The errors for the magnetic entropy change in Fig. 5(b) were estimated using the method described by Pecharsky and Gschneidner Jr. [43]. Following [43], the accuracy of the magnetisation measurement is assumed to be $\delta M_{k}=0.005 M_{k}$, the value for magnetic field is $\sigma H_{k}=0.001 H_{k}$, and the errors for temperature is taken as $\sigma T=0.1+0.001 T$. The relative errors in $\left|-\Delta S_{\mathrm{m}}\right|$ is presented in the inset of Fig. 5(b); the relative error in the $\left|-\Delta S_{\mathrm{m}}\right|$ around the magneto-structural transition temperature $T_{\mathrm{M}}$ is found to be $\sim 22 \%$. 
The refrigerant capacity, $R C$ - evaluated using $R C=\int_{T_{\mathrm{r} 1}}^{T_{\mathrm{r} 2}}\left|\Delta S_{\mathrm{m}}\right| d T$, where $T_{\mathrm{r} 1}$ and $T_{\mathrm{r} 2}$ are two temperatures of the half maximum of $\Delta S_{\mathrm{m}}$ - is a useful parameter in characterising the refrigerating capability of materials. For $\mathrm{Mn}\left(\mathrm{Co}_{0.96} \mathrm{Fe}_{0.04}\right) \mathrm{Ge}$, the $R C$ value is estimated as $187(30) \mathrm{J} \mathrm{kg}^{-1}$ for a field change of $\mu_{0} \Delta H=5 \mathrm{~T}$. This value is smaller than that for the $\left(\mathrm{Mn}_{1-}\right.$ $\left.{ }_{x} \mathrm{Fe}_{\mathrm{x}}\right)$ CoGe samples $(\mathrm{x}=0.01,0.02,0.03$ and 0.04$)$ [28], but comparable with the value of $\sim 184 \mathrm{~J} \mathrm{~kg}^{-1}$ reported for $\mathrm{MnCoGe}_{0.95} \mathrm{Ga}_{0.05}$ [22].

\subsection{Nature of magneto-structural transition - Master curve analysis}

The nature of the magneto-structural transition in the present $\mathrm{Mn}\left(\mathrm{Co}_{0.96} \mathrm{Fe}_{0.04}\right) \mathrm{Ge}$ sample has been investigated by both Arrott plot and master curve methods of analysis. Arrott plots $\left(M^{2}\right.$ versus $\left.\mu_{0} H / M\right)[44,45]$ have been used extensively to investigate the nature of phase transitions in a variety of materials. The Arrott plots for $\mathrm{Mn}\left(\mathrm{Co}_{0.96} \mathrm{Fe}_{0.04}\right) \mathrm{Ge}$ (Fig. 6(a)) present positive slopes; this finding suggests that the magneto-structural transition would be second-order, in contradiction with the hysteresis observed in the magnetisation curves (Fig. 1). In contrast, fitting the peak values of the magnetic entropy change to the relation $\Delta S_{\mathrm{m}}^{\text {peak }} \propto\left(\mu_{0} H\right)^{\mathrm{n}}$ leads to the value $\mathrm{n}=0.845$ (Fig. 6(b)). This value deviates from the exponent $n=2 / 3$ expected for a second-order phase transition [46]. As a result it is therefore problematic to use Arrott plots as an effective method to determine the nature of the magneto-structural transition $[30,47]$.

Recently, a new method - master curves of magnetic entropy changes - has been developed for exploration of the nature of magneto-structural transitions [31, 48]. It is considered that normalised magnetic entropy change curves versus rescaled temperature as defined in Eq. 5 (see below) will collapse into a single master curve for a second-order phase transition, while no master curve can be obtained for a first-order phase transition [31, 48]. 
Normalisation for the magnetic entropy changes was done based on the relation $\Delta S_{\mathrm{m}} / \Delta S_{\mathrm{m}}^{\text {peak }}$, with the rescaled temperature $\theta$ defined as [48]:

$$
\theta=\left\{\begin{array}{cl}
-\left(T-T_{\text {peak }}\right) /\left(T_{\mathrm{r} 1}-T_{\text {peak }}\right) & T \ll T_{\text {peak }} \\
\left(T-T_{\text {peak }}\right) /\left(T_{\mathrm{r} 2}-T_{\text {peak }}\right) & T>T_{\text {peak }}
\end{array}\right.
$$

$T_{\mathrm{r} 1}$ and $T_{\mathrm{r} 2}$ are two reference temperatures corresponding to the half magnetic entropy change peak and $T_{\mathrm{r} 1}<T_{\text {peak }}<T_{\mathrm{r} 2}$. The normalised magnetic entropy changes (for field changes in the range $\mu_{0} \Delta H=0 \mathrm{~T}$ to $\mu_{0} \Delta H=8 \mathrm{~T}$ ) versus rescaled temperature are shown in Fig. 6(c). No single master curves were obtained. This result is similar to the behaviour reported for $\mathrm{Mn}_{1.1} \mathrm{Fe}_{0.9} \mathrm{P}_{0.6} \mathrm{Si}_{0.25} \mathrm{Ge}_{0.15}$ [48], and together with the thermal hysteresis in Fig. 1, confirms that the magneto-structural transition in $\mathrm{Mn}\left(\mathrm{Co}_{0.96} \mathrm{Fe}_{0.04}\right) \mathrm{Ge}$ is first-order.

\section{CONCLUSIONS:}

The effect of substitution of $\mathrm{Fe}$ for $\mathrm{Co}$ in $\mathrm{Mn}\left(\mathrm{Co}_{0.96} \mathrm{Fe}_{0.04}\right) \mathrm{Ge}$ has been investigated by variable temperature $\mathrm{x}$-ray diffraction, neutron diffraction and magnetisation measurements. Irreducible representation analysis and Rietveld refinements of the neutron data indicated that the as-prepared $\mathrm{Mn}\left(\mathrm{Co}_{0.96} \mathrm{Fe}_{0.04}\right) \mathrm{Ge}$ sample has a ferromagnetic structure with magnetic moments on the Mn sublattice in the orthorhombic phase. In addition, the neutron diffraction experiments demonstrated directly the occurrence of a magneto-structural transition at $T_{\mathrm{M}}=$ 299(1) K from the low-temperature ferromagnetic orthorhombic phase to the hightemperature paramagnetic hexagonal phase. The increased occupancy by Fe of the Co (4c) site rather than the $\mathrm{Mn}(4 \mathrm{c})$ site correlates with a smaller suppression of the structural transition temperature (compared with undoped $\mathrm{MnCoGe}$ ) to $T_{\mathrm{M}}=299(1) \mathrm{K}$ in $\mathrm{Mn}\left(\mathrm{Co}_{0.96} \mathrm{Fe}_{0.04}\right) \mathrm{Ge}$ compared with $T_{\mathrm{M}}=239(1) \mathrm{K}$ in as-prepared $\left(\mathrm{Mn}_{0.96} \mathrm{Fe}_{0.04}\right) \mathrm{CoGe}\left({ }^{57} \mathrm{Fe}\right)$ [29]. In addition, the chemical pressure due to doping of Fe raises the Curie temperature $T_{C}^{\text {orth }}$ by $20 \mathrm{~K}$. 
A large magnetocaloric effect is obtained, e.g. isothermal magnetic entropy change is $-\Delta S_{\mathrm{m}}^{\text {peak }}=11(2) \mathrm{J} \mathrm{kg}^{-1} \mathrm{~K}^{-1}$ and refrigeration capacity is $R C=187(30) \mathrm{J} \mathrm{kg}^{-1}$ with $\mu_{0} \Delta H=5 \mathrm{~T}$ around the magneto-structural transition. Master curve analysis has established that the magneto-structural transition at $T_{\mathrm{M}}=299(1) \mathrm{K}$ in $\mathrm{Mn}\left(\mathrm{Co}_{0.96} \mathrm{Fe}_{0.04}\right) \mathrm{Ge}$ is first-order as also indicated by thermal hysteresis in the magnetisation curves.

\section{ACKNOWLEDGEMENTS:}

This work was supported in part by grants from the Australian Research Council: (Discovery project DP110102386) and LIEF grant LE1001000177. QYR is grateful to the UNSW Canberra for a Research Training Scholarship and Research Publication Fellowship. 


\section{REFERENCES}

[1] E. Brück, Developments in magnetocaloric refrigeration, J. Phys. D: Appl. Phys., 38 (2005) R381R391.

[2] K.A. Gschneidner Jr, V.K. Pecharsky, A.O. Tsokol, Recent developments in magnetocaloric materials, Rep. Prog. Phys., 68 (2005) 1479-1539.

[3] O. Gutfleisch, M.A. Willard, E. Bruck, C.H. Chen, S.G. Sankar, J.P. Liu, Magnetic materials and devices for the 21st century: stronger, lighter, and more energy efficient, Adv. Mater., 23 (2011) 821-842.

[4] V.K. Pecharsky, K.A. Gschneidner Jr, Giant Magnetocaloric Effect in $\mathrm{Gd}_{5}\left(\mathrm{Si}_{2} \mathrm{Ge}_{2}\right)$, Phys. Rev. Lett., 78 (1997) 4494-4497.

[5] B.G. Shen, J.R. Sun, F.X. Hu, H.W. Zhang, Z.H. Cheng, Recent Progress in Exploring Magnetocaloric Materials, Adv. Mater., 21 (2009) 4545-4564.

[6] N.H. Dung, Z.Q. Ou, L. Caron, L. Zhang, D.T.C. Thanh, G.A. de Wijs, R.A. de Groot, K.H.J. Buschow, E. Brück, Mixed Magnetism for Refrigeration and Energy Conversion, Adv. Eng. Mater., 1 (2011) 1215-1219.

[7] A. de Campos, D.L. Rocco, A.M. Carvalho, L. Caron, A.A. Coelho, S. Gama, L.M. da Silva, F.C. Gandra, A.O. dos Santos, L.P. Cardoso, P.J. von Ranke, N.A. de Oliveira, Ambient pressure colossal magnetocaloric effect tuned by composition in $\mathrm{Mn}_{1-\mathrm{x}} \mathrm{Fe}_{x} \mathrm{As}$, Nat. Mater., 5 (2006) 802.

[8] J. Liu, T. Gottschall, K.P. Skokov, J.D. Moore, O. Gutfleisch, Giant magnetocaloric effect driven by structural transitions, Nat. Mater., 11 (2012) 620-626.

[9] N.T. Trung, L. Zhang, L. Caron, K.H.J. Buschow, E. Brück, Giant magnetocaloric effects by tailoring the phase transitions, Appl. Phys. Lett., 96 (2010) 172504.

[10] V. Johnson, Diffusionless orthorhombic to hexagonal transitions in ternary silicides and germanides, Inorg. Chem., 14 (1975) 1117-1120.

[11] T. Kanomata, H. Ishigaki, T. Suzuki, H. Yoshida, S. Abe, T. Kaneko, Magneto-volume effect of $\mathrm{MnCo}_{1-\mathrm{x}} \mathrm{Ge}(0 \leqslant \mathrm{x} \leqslant 0.2)$, J. Magn. Magn. Mater., 140-144, Part 1 (1995) 131-132.

[12] S. Nizioł, A. Zięba, R. Zach, M. Baj, L. Dmowski, Structural and magnetic phase transitions in $\mathrm{Co}_{x} \mathrm{Ni}_{1-x} \mathrm{MnGe}$ system under pressure, J. Magn. Magn. Mater., 38 (1983) 205-213.

[13] Y.K. Fang, J.C. Yeh, W.C. Chang, X.M. Li, W. Li, Structures, magnetic properties, and magnetocaloric effect in $\mathrm{MnCo}_{1-\mathrm{x}} \mathrm{Ge}(0.02 \leqslant \mathrm{x} \leqslant 0.2)$ compounds, J. Magn. Magn. Mater., 321 (2009) 3053-3056.

[14] E.K. Liu, W. Zhu, L. Feng, J.L. Chen, W.H. Wang, G.H. Wu, H.Y. Liu, F.B. Meng, H.Z. Luo, Y.X. Li, Vacancy-tuned paramagnetic/ferromagnetic martensitic transformation in $\mathrm{Mn}$-poor $\mathrm{Mn}_{1-\mathrm{x}} \mathrm{CoGe}$ alloys, Europhys. Lett., 91 (2010) 17003.

[15] S. Nizioł, R. Zach, J.P. Senateur, J. Beille, Pressure dependence of the magnetic transition temperature of the $\mathrm{CoMnGe}_{1-\mathrm{x}} \mathrm{Si}_{x}$ system, J. Magn. Magn. Mater., 79 (1989) 333-337.

[16] W. Zhang, O. Tegus, Y. Wu, Yirgeltu, H. Yan, S. Lin, Magnetocaloric Effect in $\mathrm{MnCo}_{1-x} \mathrm{Al}{ }_{x} \mathrm{Ge}$ Compounds, J. Mater. Sci. Technol., 25 (2009) 781-784.

[17] J.B.A. Hamer, R. Daou, S. Özcan, N.D. Mathur, D.J. Fray, K.G. Sandeman, Phase diagram and magnetocaloric effect of alloys, J. Magn. Magn. Mater., 321 (2009) 3535-3540.

[18] N.T. Trung, V. Biharie, L. Zhang, L. Caron, K.H.J. Buschow, E. Brück, From single- to double-firstorder magnetic phase transition in magnetocaloric $\mathrm{Mn}_{1-\mathrm{x}} \mathrm{Cr}_{x} \mathrm{CoGe}$ compounds, Appl. Phys. Lett., 96 (2010) 162507.

[19] G.H. Meng, O. Tegus, W.G. Zhang, L. Song, J.H. Huang, Structural and magnetic properties of $\mathrm{MnCo}_{1-\mathrm{x}} \mathrm{V}_{\mathrm{x}} \mathrm{Ge}$ compounds, J. Alloys Compd., 497 (2010) 14-16.

[20] L. Caron, N.T. Trung, E. Brück, Pressure-tuned magnetocaloric effect in $\mathrm{Mn}_{0.93} \mathrm{Cr}_{0.07} \mathrm{CoGe}$, Phys. Rev. B, 84 (2011) 020414(R).

[21] S.C. Ma, Y.X. Zheng, H.C. Xuan, L.J. Shen, Q.Q. Cao, D.H. Wang, Z.C. Zhong, Y.W. Du, Large roomtemperature magnetocaloric effect with negligible magnetic hysteresis losses in $\mathrm{Mn}_{1-\mathrm{x}} \mathrm{V}_{\mathrm{x}} \mathrm{CoGe}$ alloys, J. Magn. Magn. Mater., 324 (2012) 135-139. 
[22] I. Dincer, E. Yüzüak, G. Durak, Y. Elerman, A.M.T. Bell, H. Ehrenberg, Exploring the details of the martensitic phase transition and magnetocaloric effect of $\mathrm{CoMnGe}_{0.95} \mathrm{Ga}_{0.05}$ by synchrotron and magnetic measurements, J. Alloys Compd., 540 (2012) 236-240.

[23] K. Koyama, M. Sakai, T. Kanomata, K. Watanabe, Field-Induced Martensitic Transformation in New Ferromagnetic Shape Memory Compound $\mathrm{Mn}_{1.07} \mathrm{Co}_{0.92} \mathrm{Ge}$, Jpn. J. Appl. Phys., 43 (2004) 80368039.

[24] G.J. Li, E.K. Liu, H.G. Zhang, Y.J. Zhang, J.L. Chen, W.H. Wang, H.W. Zhang, G.H. Wu, S.Y. Yu, Phase diagram, ferromagnetic martensitic transformation and magnetoresponsive properties of $\mathrm{Fe}-$ doped MnCoGe alloys, J. Magn. Magn. Mater., 332 (2013) 146-150.

[25] T. Samanta, I. Dubenko, A. Quetz, J. Prestigiacomo, P.W. Adams, S. Stadler, N. Ali, $\mathrm{Mn}_{1-x} \mathrm{Fe}_{x} \mathrm{CoGe:}$ A strongly correlated metal in the proximity of a noncollinear ferromagnetic state, Appl. Phys. Lett., 103 (2013) 042408.

[26] Q.Y. Ren, W.D. Hutchison, J.L. Wang, S. Muñoz Pérez, J.M. Cadogan, S.J. Campbell, Magnetism and magnetocaloric effect of $\mathrm{Mn}_{0.98} \mathrm{Fe}_{0.02} \mathrm{CoGe}$, Phys. Status Solidi A, 211 (2014); Phys. Status Solidi (a) 211(12), 2898-2899 (2014) 1101-1105.

[27] E. Yüzüak, I. Dincer, Y. Elerman, I. Dumkow, B. Heger, S. Yuce Emre, Enhancement of Magnetocaloric Effect in CoMn ${ }_{0.9} \mathrm{Fe}_{0.1} \mathrm{Ge}$ alloy, J. Alloys Compd., 641 (2015) 69-73.

[28] Q.Y. Ren, W.D. Hutchison, J.L. Wang, A.J. Studer, M.F.M. Din, S.M. Pérez, J.M. Cadogan, S.J. Campbell, The magneto-structural transition in $\mathrm{Mn}_{1-x} \mathrm{Fe}_{x} \mathrm{CoGe}$, J. Phys. D: Appl. Phys., 49 (2016) 175003.

[29] Q.Y. Ren, W.D. Hutchison, J.L. Wang, R. Cobas, J.M. Cadogan, S.J. Campbell, A 57Fe Mössbauer study of magnetocaloric Fe doped MnCoGe, Hyperfine Interact., 231 (2015) 75-84.

[30] V. Franco, J.S. Blázquez, A. Conde, Field dependence of the magnetocaloric effect in materials with a second order phase transition: A master curve for the magnetic entropy change, Appl. Phys. Lett., 89 (2006) 222512.

[31] C.M. Bonilla, J. Herrero-Albillos, F. Bartolomé, L.M. García, M. Parra-Borderías, V. Franco, Universal behavior for magnetic entropy change in magnetocaloric materials: An analysis on the nature of phase transitions, Phys. Rev. B, 81 (2010) 224424.

[32] H. Rietveld, A profile refinement method for nuclear and magnetic structures, J. Appl. Cryst., 2 (1969) 65-71.

[33] J. Rodríguez-Carvajal, Recent advances in magnetic structure determination by neutron powder diffraction, Physica B: Condensed Matter, 192 (1993) 55-69.

[34] E. Bertaut, Representation analysis of magnetic structures, Acta Cryst., A24 (1968) 217-231.

[35] S.V. Gallego, E.S. Tasci, G. de la Flor, J.M. Perez-Mato, M.I. Aroyo, Magnetic symmetry in the Bilbao Crystallographic Server: a computer program to provide systematic absences of magnetic neutron diffraction, J. Appl. Cryst., 45 (2012) 1236-1247.

[36] K.A. Gschneidner, Y. Mudryk, V.K. Pecharsky, On the nature of the magnetocaloric effect of the first-order magnetostructural transition, Scripta Mater., 67 (2012) 572-577.

[37] Y.Y. Zhao, F.X. Hu, L.F. Bao, J. Wang, H. Wu, Q.Z. Huang, R.R. Wu, Y. Liu, F.R. Shen, H. Kuang, M. Zhang, W.L. Zuo, X.Q. Zheng, J.R. Sun, B.G. Shen, Giant Negative Thermal Expansion in Bonded MnCoGe-Based Compounds with $\mathrm{Ni}_{2}$ In-Type Hexagonal Structure, J. Am. Chem. Soc., 137 (2015) 1746-1749.

[38] H. Zhao, H. Kimura, Z. Cheng, M. Osada, J. Wang, X. Wang, S. Dou, Y. Liu, J. Yu, T. Matsumoto, T. Tohei, N. Shibata, Y. Ikuhara, Large magnetoelectric coupling in magnetically short-range ordered $\mathrm{Bi}_{5} \mathrm{Ti}_{3} \mathrm{FeO}_{15}$ film, Sci. Rep., 4 (2014) 5255.

[39] S. Kennedy, J. Wang, S. Campbell, M. Hofmann, S. Dou, Pressure induced magneto-structural phase transitions in layered $\mathrm{RMn}_{2} \mathrm{X}_{2}$ compounds (invited), J. Appl. Phys., 115 (2014) 172617.

[40] J.L. Wang, P. Shamba, W.D. Hutchison, Q.F. Gu, M.F. Md Din, Q.Y. Ren, Z.X. Cheng, S.J. Kennedy, S.J. Campbell, S.X. Dou, Magnetocaloric Effect and Magnetostructural Coupling in $\mathrm{Mn}_{0.92} \mathrm{Fe}_{0.08} \mathrm{CoGe}$ Compound, J. Appl. Phys., 117 (2015) 17D103. 
[41] E. Liu, W. Wang, L. Feng, W. Zhu, G. Li, J. Chen, H. Zhang, G. Wu, C. Jiang, H. Xu, F. de Boer, Stable magnetostructural coupling with tunable magnetoresponsive effects in hexagonal ferromagnets, Nat. Commun., 3 (2012) 873.

[42] D. Choudhury, T. Suzuki, Y. Tokura, Y. Taguchi, Tuning structural instability toward enhanced magnetocaloric effect around room temperature in $\mathrm{MnCo}_{1-x} \mathrm{Zn}_{x} \mathrm{Ge}$, Sci. Rep., 4 (2014) 07544.

[43] V.K. Pecharsky, K.A. Gschneidner Jr, Magnetocaloric effect from indirect measurements: Magnetization and heat capacity, J. Appl. Phys., 86 (1999) 565.

[44] S.K. Banerjee, On a generalised approach to first and second order magnetic transitions, Phys. Lett., 12 (1964) 16-17.

[45] J.L. Wang, S.J. Campbell, J.M. Cadogan, A.J. Studer, R. Zeng, S.X. Dou, Magnetocaloric effect in layered $\mathrm{NdMn}_{2} \mathrm{Ge}_{0.4} \mathrm{Si}_{1.6}$, Appl. Phys. Lett., 98 (2011) 232509.

[46] H. Oesterreicher, F.T. Parker, Magnetic cooling near Curie temperatures above $300 \mathrm{~K}$, J. Appl. Phys., 55 (1984) 4334.

[47] V. Franco, J.S. Blázquez, A. Conde, The influence of Co addition on the magnetocaloric effect of Nanoperm-type amorphous alloys, J. Appl. Phys., 100 (2006) 064307.

[48] G.F. Wang, Z.R. Zhao, X.F. Zhang, L. Song, O. Tegus, Analysis of the first-order phase transition of $(\mathrm{Mn}, \mathrm{Fe})_{2}(\mathrm{P}, \mathrm{Si}, \mathrm{Ge})$ using entropy change scaling, J. Phys. D: Appl. Phys., 46 (2013) 295001. 


\section{TABLES}

Table 1 Irreducible representation analysis for the $4 \mathrm{c}$ site in the orthorhombic structure $(P n m a)$ with a propagation vector $\left[\begin{array}{lll}0 & 0 & 0\end{array}\right]$. The atomic position for the $4 \mathrm{c}$ site are $(\mathrm{x}, 1 / 4, \mathrm{y}),(1 / 2$ $-\mathrm{x}, 3 / 4,1 / 2+z),(-x, 3 / 4,-z)$, and $(1 / 2+x, 1 / 4,-z)$.

\begin{tabular}{ccccc}
\hline \hline Representation & Ordering mode & \multicolumn{3}{c}{ Magnetic moment directions } \\
$\Gamma_{1}$ & $\mathrm{G}_{\mathrm{y}}$ & $\mathrm{x}$ & $\mathrm{y}$ & $\mathrm{z}$ \\
$\Gamma_{2}$ & $\mathrm{~A}_{\mathrm{x}} \mathrm{C}_{\mathrm{z}}$ & +--+ & +-+- & ++-- \\
$\Gamma_{3}$ & $\mathrm{G}_{\mathrm{x}} \mathrm{F}_{\mathrm{z}}$ & +-+- & & ++++ \\
$\Gamma_{4}$ & $\mathrm{~A}_{\mathrm{y}}$ & & +-+ & \\
$\Gamma_{5}$ & $\mathrm{~F}_{\mathrm{y}}$ & & ++++ & +-+ \\
$\Gamma_{6}$ & $\mathrm{C}_{\mathrm{x}} \mathrm{A}_{\mathrm{z}}$ & ++-- & & +-+- \\
$\Gamma_{7}$ & $\mathrm{~F}_{\mathrm{x}} \mathrm{G}_{\mathrm{z}}$ & ++++ & & \\
$\Gamma_{8}$ & $\mathrm{C}_{\mathrm{y}}$ & & ++- & \\
\hline \hline
\end{tabular}


Table 2 The crystallographic and magnetic data of $\mathrm{Mn}\left(\mathrm{Co}_{0.96} \mathrm{Fe}_{0.04}\right) \mathrm{Ge}$ from Rietveld refinement of neutron diffraction patterns at selected temperatures: $450 \mathrm{~K}, 300 \mathrm{~K}$ and $5 \mathrm{~K}$.

\begin{tabular}{|c|c|c|c|c|c|c|}
\hline Temperature (K) & \multicolumn{2}{|c|}{$450 \mathrm{~K}$} & \multicolumn{2}{|c|}{$300 \mathrm{~K}$} & \multicolumn{2}{|c|}{$5 \mathrm{~K}$} \\
\hline Phase & Orth. & Hex. & Orth. & Hex. & Orth. & Hex. \\
\hline Space group & Pnma & $\mathrm{Pb}_{3} / \mathrm{mmc}$ & Pnma & $\mathrm{PG}_{3} / m m c$ & Pnma & $\mathrm{Pb}_{3} / m m c$ \\
\hline$a(\AA)$ & $5.95(3)$ & 4.094(1) & $5.929(1)$ & $4.071(2)$ & $5.878(1)$ & $4.088(9)$ \\
\hline$b(\AA)$ & $3.82(2)$ & & $3.825(1)$ & & $3.818(1)$ & \\
\hline$c(\AA)$ & $7.06(4)$ & $5.342(1)$ & $7.052(2)$ & $5.309(1)$ & $7.050(1)$ & $5.34(2)$ \\
\hline$V\left(\AA^{3}\right)$ & $161(2)$ & $77.54(2)$ & $159.91(7)$ & $76.78(2)$ & $158.24(5)$ & $77.2(4)$ \\
\hline Pass fraction (wt $\%)$ & $3(1)$ & $97(3)$ & $48(2)$ & $52(2)$ & $98(3)$ & $2.4(5)$ \\
\hline Magnetic state & paramagnetic & paramagnetic & ferromagnetic & paramagnetic & ferromagnetic & ferromagnetic \\
\hline Moment carrier & - & - & $\mathrm{Mn}$ & - & $\mathrm{Mn}$ & - \\
\hline Moment value $\left(\mu_{\mathrm{B}}\right)$ & - & - & $2.3(2)$ & - & $3.6(1)$ & - \\
\hline $\mathrm{R}_{\mathrm{p}}, \mathrm{R}_{\mathrm{wp}}$ & 2.01, & 2.55 & 1.73 & 2.19 & 2.07 & 2.64 \\
\hline $\mathrm{R}_{\mathrm{exp}}, \chi^{2}$ & 1.38, & 3.39 & 1.40 & 2.44 & 1.35 & 3.61 \\
\hline
\end{tabular}


Table 3 Magnetic moment per formula $\left(\mu_{\mathrm{B}} / \mathrm{f}\right.$.u $)$ in $\mathrm{Mn}\left(\mathrm{Co}_{0.96} \mathrm{Fe}_{0.04}\right) \mathrm{Ge}$ as determined from Rietveld refinement of neutron powder diffraction patterns and from the saturated magnetisation, respectively.

\begin{tabular}{cccc}
\hline \hline & Neutron $^{\dagger}$ & Neutron $^{\ddagger}$ & Magnetisation \\
$5 \mathrm{~K}$ & $4.1(1)$ & $3.6(1)$ & $3.65(2)$ \\
$100 \mathrm{~K}$ & $3.9(1)$ & $3.5(1)$ & $3.48(2)$ \\
$200 \mathrm{~K}$ & $3.4(1)$ & $3.1(1)$ & $3.11(2)$ \\
$240 \mathrm{~K}$ & $3.1(1)$ & $2.8(1)$ & $2.92(2)$ \\
\hline \hline
\end{tabular}

${ }^{\dagger}$ Refined values assuming both $\mathrm{Mn}$ and Co sublattices carry magnetic moments.

$\ddagger$ Refined values assuming only Mn sublattice carries a magnetic moment. 


\section{FIGURE CAPTION}

Fig. 1 (colour online) Magnetisation curves for as-prepared $\mathrm{Mn}\left(\mathrm{Co}_{0.96} \mathrm{Fe}_{0.04}\right) \mathrm{Ge}$ in a field of $0.01 \mathrm{~T}$ over the temperature range $5 \mathrm{~K}$ to $320 \mathrm{~K}$ (ZFC - zero field cooling; FC - field cooling; FH - field heating).

Fig. 2 (colour online) (a) Thermal contour image of the neutron diffraction patterns for asprepared $\mathrm{Mn}\left(\mathrm{Co}_{0.96} \mathrm{Fe}_{0.04}\right) \mathrm{Ge}$ upon heating $(\lambda=2.4205 \AA)$. (b) Neutron diffraction patterns at selected temperatures used to trace variations of the peak intensities in the orthorhombic structure below $250 \mathrm{~K}$. (c) The variations of the intensities of the orthorhombic $(011)^{\text {orth }}$ peak (at $2 \theta \sim 42^{\circ}$ below $\sim 320 \mathrm{~K}$ ) and the hexagonal $(002)^{\text {hex }}$ peak (at $2 \theta \sim 54^{\circ}$ above $\sim 275 \mathrm{~K}$ ).

Fig. 3 (colour online) Rietveld refinements of the neutron diffraction patterns for as-prepared $\mathrm{Mn}\left(\mathrm{Co}_{0.96} \mathrm{Fe}_{0.04}\right) \mathrm{Ge}$ collected at (a) $5 \mathrm{~K}$, (b) $300 \mathrm{~K}$ and (c) $450 \mathrm{~K}$. The horizontal rows of Bragg markers (top to bottom) represent: the nuclear structure of the orthorhombic phase, the magnetic structure of the orthorhombic phase and the nuclear structure of the hexagonal phase. The bottom blue solid lines are the difference between observed (red circles) and calculated (black solid line) data. The excluded regions are related to background noise.

Fig. 4 (colour online) (a) Temperature dependences of lattice parameters and unit cell volume of as-prepared $\mathrm{Mn}\left(\mathrm{Co}_{0.96} \mathrm{Fe}_{0.04}\right) \mathrm{Ge}$ across the structural transition based on the analysis of the neutron diffraction data. (b) Phase fraction evolutions with temperature of the orthorhombic (solid star) and hexagonal (open star) phases. (c) Magnetic moment (open diamond) on the Mn sublattice in the orthorhombic phase and the fit (dash line) based on a Brillouin function. The vertical short-dash lines are inserted as indicators of the structural transition temperature $T_{\mathrm{M}}$

Fig. 5 (colour online) (a) Isothermal magnetisation curves for the as-prepared $\mathrm{Mn}\left(\mathrm{Co}_{0.96} \mathrm{Fe}_{0.04}\right) \mathrm{Ge}$ with increasing magnetic field from $0 \mathrm{~T}$ to $8 \mathrm{~T}$; and (b) corresponding 
magnetic entropy change with magnetic field changes of $2 \mathrm{~T}$ and $5 \mathrm{~T}$ and estimated errors shown as error bars. Inset is the corresponding relative errors in $\left|-\Delta S_{\mathrm{m}}\right|(\%)$.

Fig. 6 (colour online) (a) Arrott plots for the as-prepared $\mathrm{Mn}\left(\mathrm{Co}_{0.96} \mathrm{Fe}_{0.04}\right) \mathrm{Ge}$ around the martensitic reverse transformation temperature $T_{\mathrm{M}}=299(1) \mathrm{K}$. (b) Graph of the peak values of $\Delta S_{\mathrm{m}}^{\text {peak }} \propto\left(\mu_{0} H\right)^{\mathrm{n}}$ for field changes from $\mu_{0} \Delta H=1 \mathrm{~T}$ to $\mu_{0} \Delta H=8 \mathrm{~T}$. The solid line leads to the exponent value $\mathrm{n}=0.845$ as discussed in the text. (c) Normalised magnetic entropy changes as a function of the rescaled temperature $\theta$ from $\mu_{0} \Delta H=1 \mathrm{~T}$ to $\mu_{0} \Delta H=8 \mathrm{~T}$. As discussed in the text, these normalised magnetic entropy changes do not collapse into a single master curve, thus indicating the first-order nature of the magneto-structural transition. 
Figure 1:

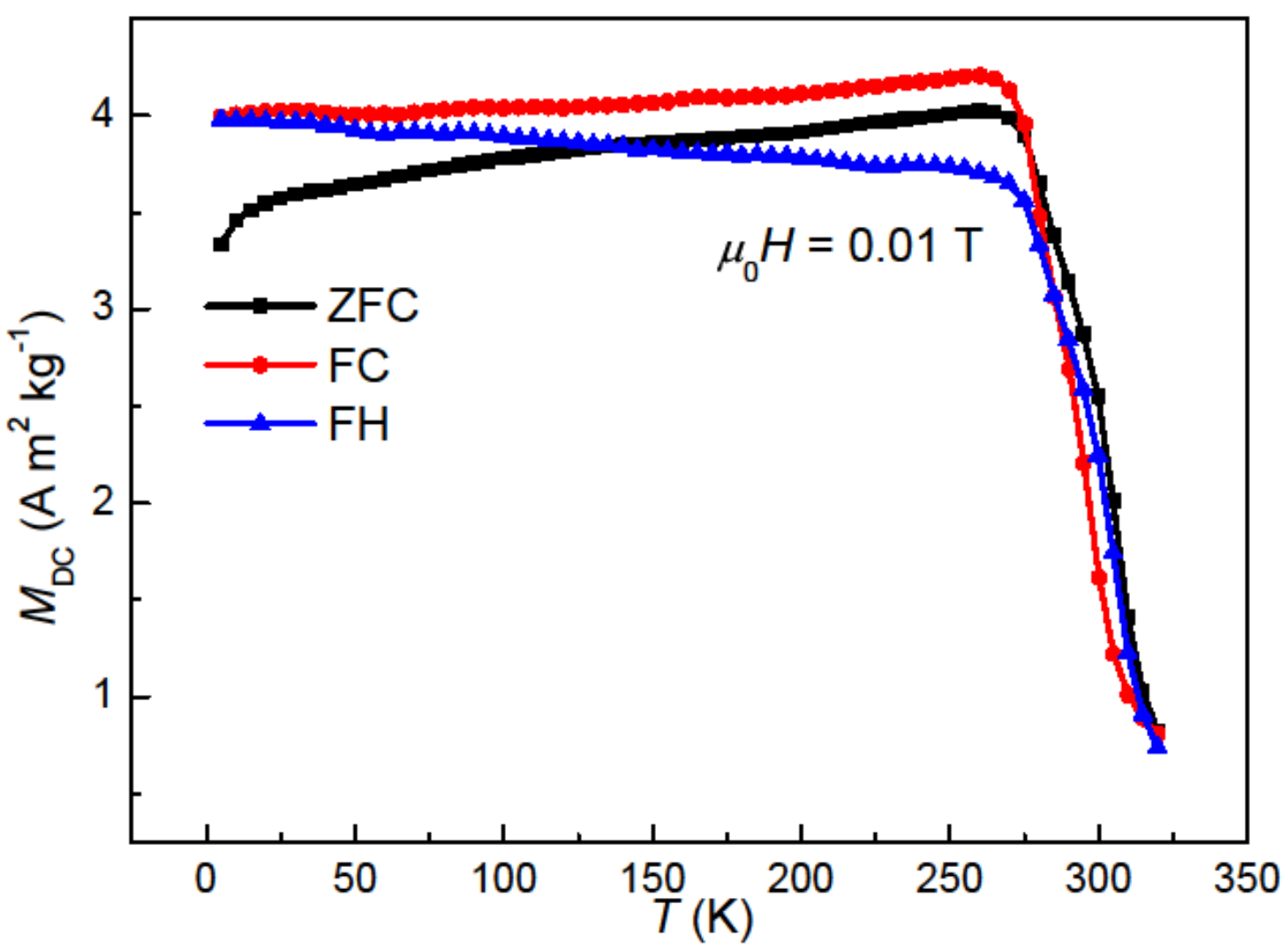


Figure 2:
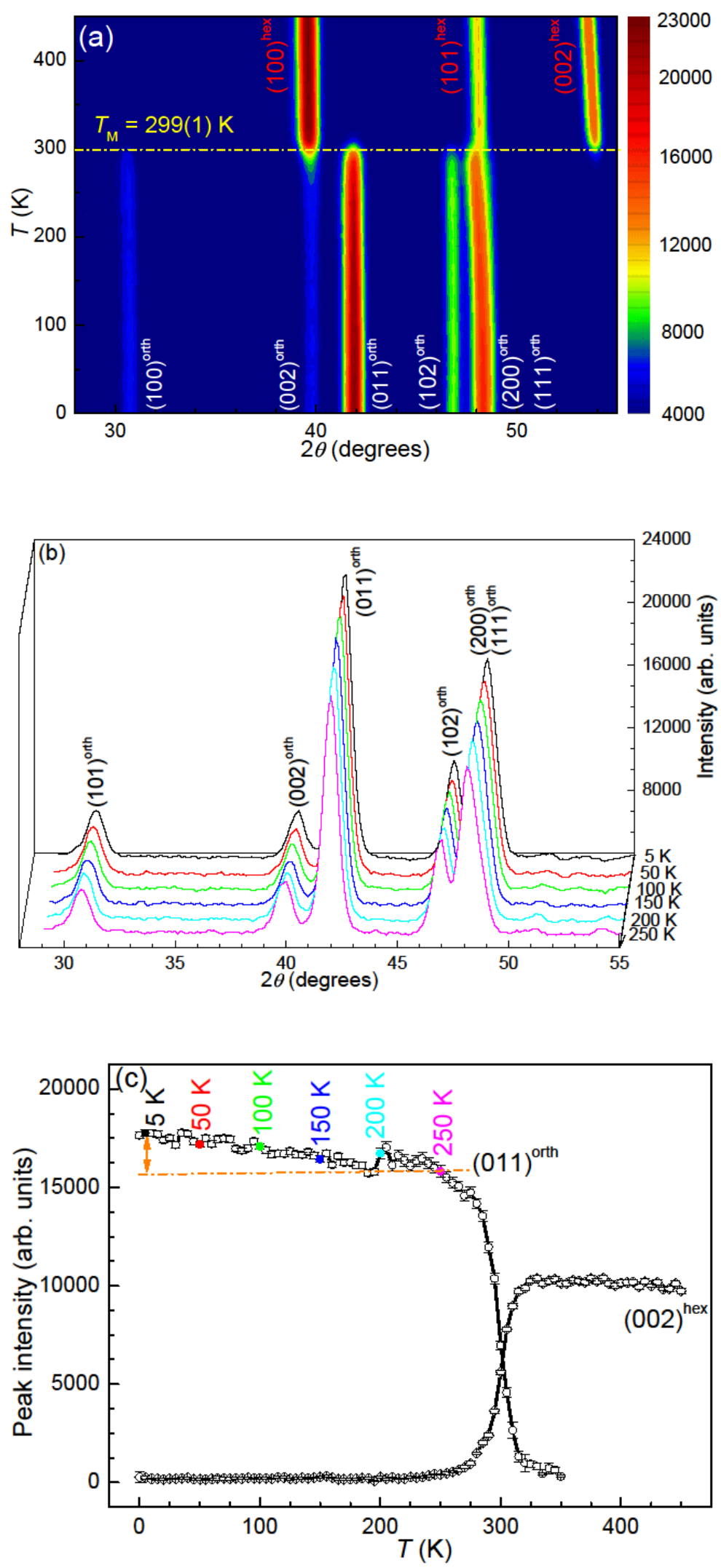
Figure 3:

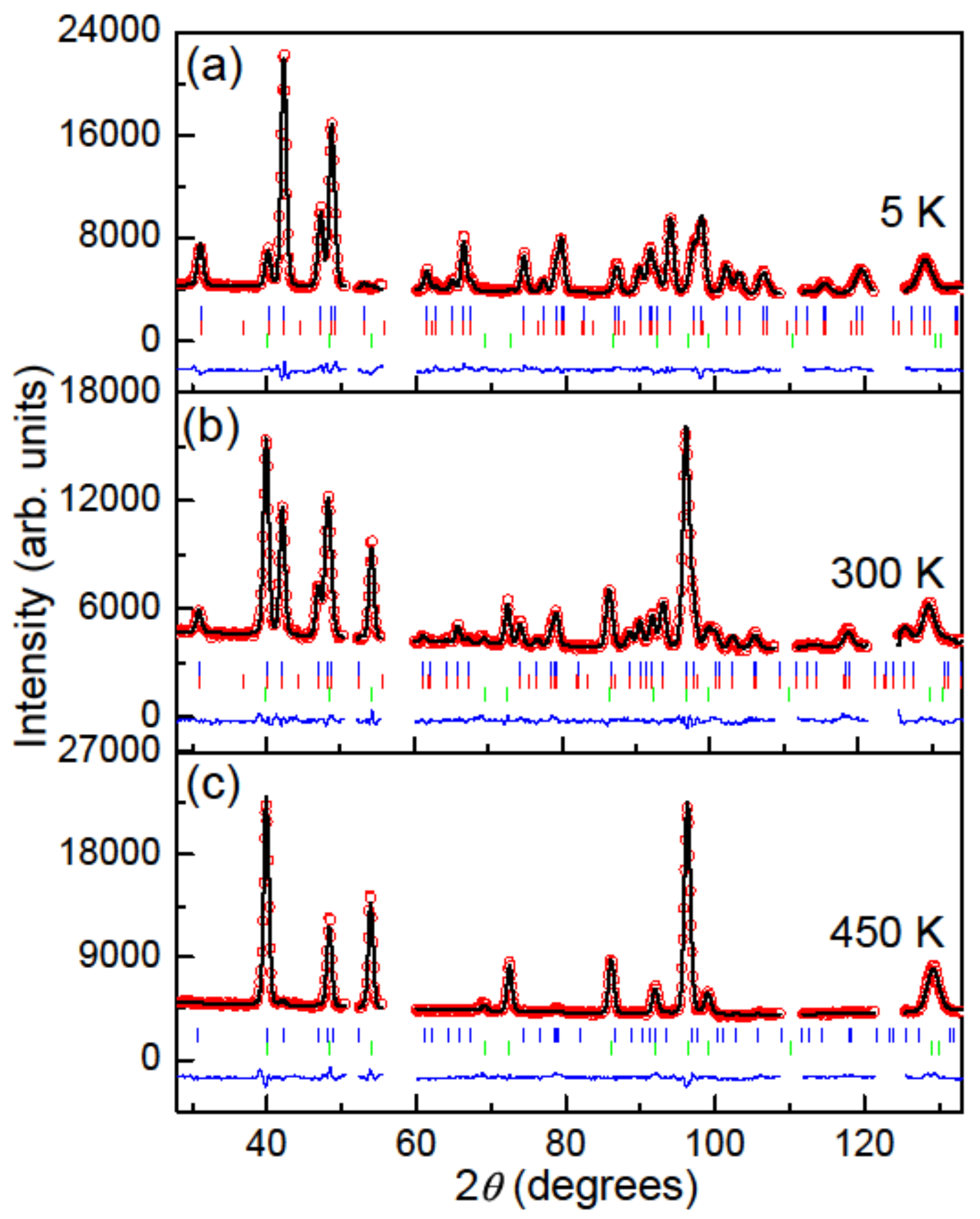


Figure 4:

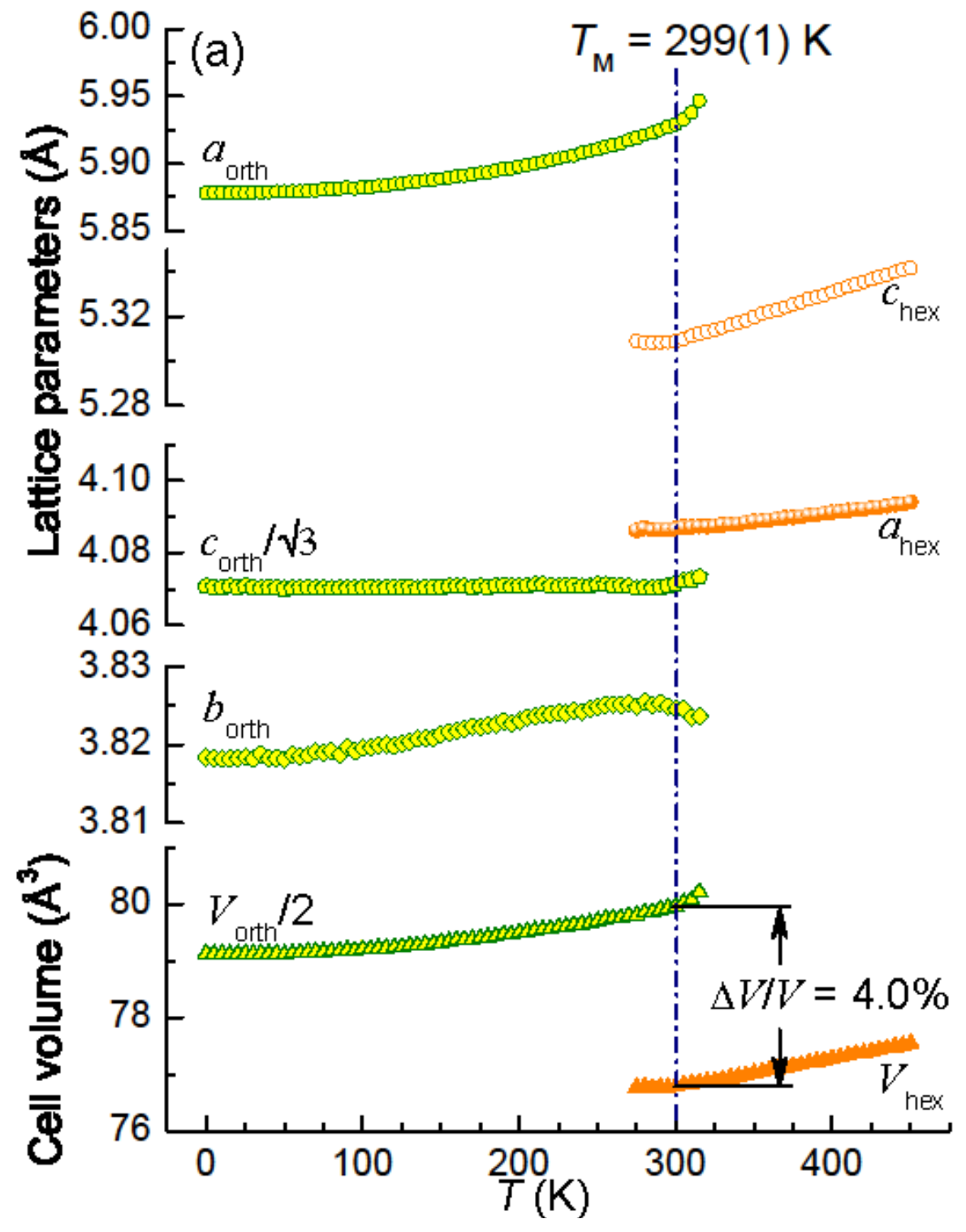




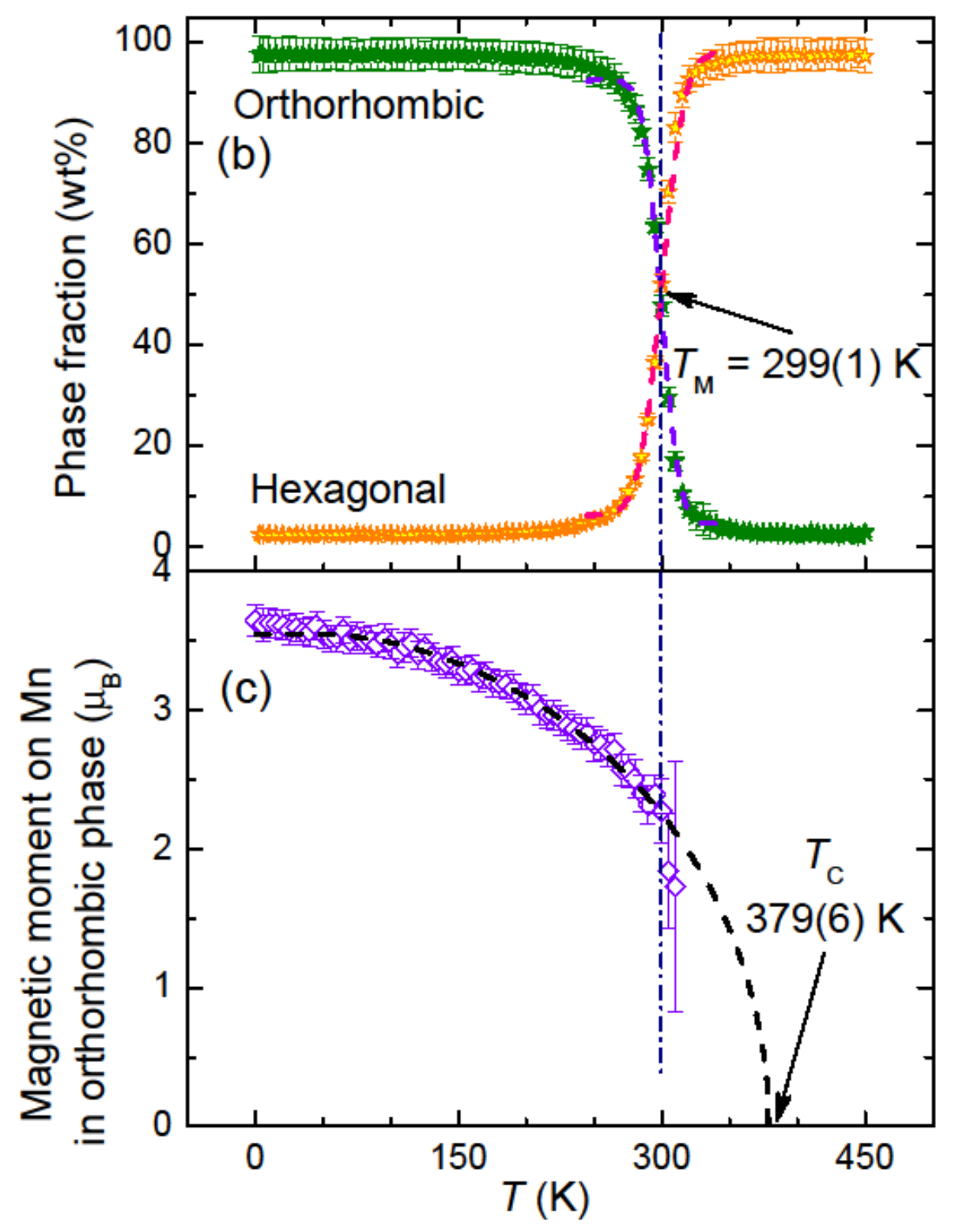


Figure 5:
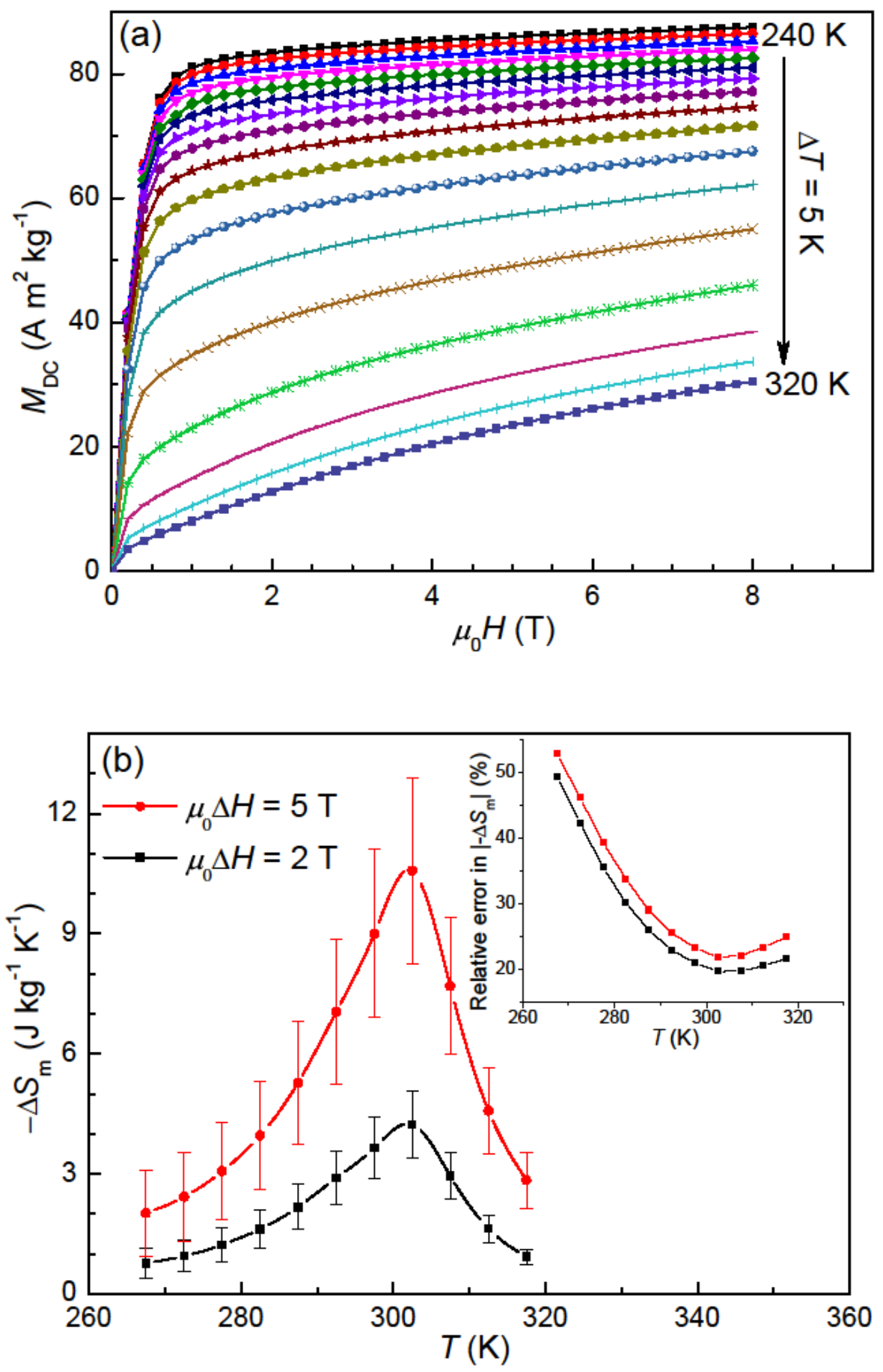
Figure 6:
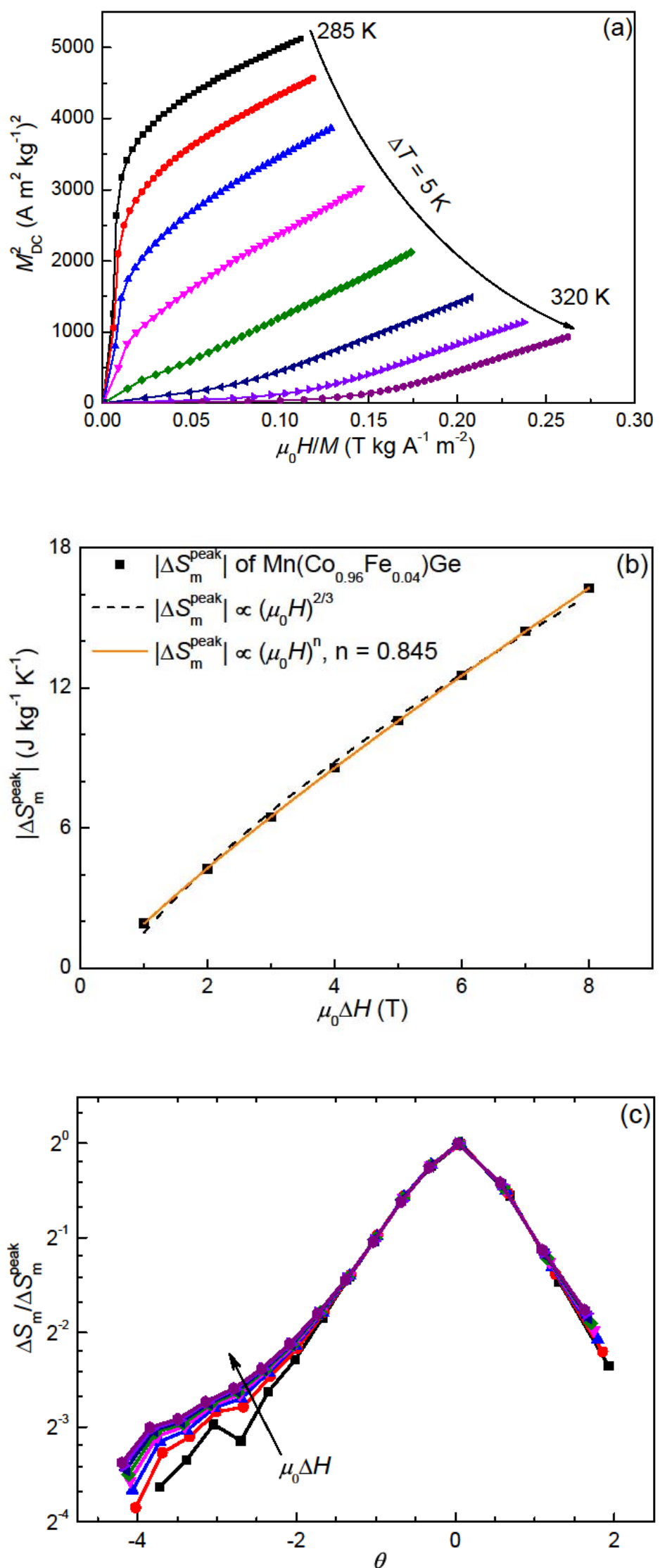

Page $\mathbf{2 8}$ of $\mathbf{2 8}$ 